\title{
SENSE OF COHERENCE VS. MENTAL LOAD IN NURSES WORKING AT A CHEMOTHERAPY WARD
}

\author{
Grażyna Dębska ${ }^{1}$, Małgorzata Pasek ${ }^{1}$, Ewa Wilczek-Rużyczka² \\ ${ }^{1}$ Faculty of Health and Medical Science, Andrzej Frycz Modrzewski Krakow University, Krakow, Poland \\ ${ }^{2}$ Faculty of Psychology and Humanities, Andrzej Frycz Modrzewski Krakow University, Krakow, Poland
}

\section{SUMMARY}

Objectives: The aim of this study was to analyze the relationship between the sense of coherence and the level of mental load among nurses working at a chemotherapy ward.

Methods: The study, conducted in 2013, included 164 nurses working at inpatient chemotherapy wards in Krakow, Poznan, Kielce, and Gliwice (Poland). The mean age of the study participants was $43.07 \pm 7.99$ years. The study was based on a diagnostic survey with Antonovsky's Sense of Coherence Scale (SOC-29) and Meister questionnaire.

Results: The levels of Mental Load, Monotony and Unspecific Load, correlated inversely with the levels of Coherence, Manageability, Meaningfulness, and Comprehensibility. Longer work experience was associated with lower levels of Coherence, Manageability and Comprehensibility and higher levels of Mental Load, Overload and Monotony. Age of nurses correlated inversely with the Manageability level. Heavy mental and physical workload turned out to be the main factor causing dissatisfaction of the study participants.

Conclusions: Longer work experience and lower levels of Coherence are associated with higher risk for mental overload.

Key words: sense of coherence, mental load, burnout, nurse, chemotherapy

Address for correspondence: G. Dębska, Andrzej Frycz Modrzewski Krakow University, Herlinga-Grudzińskiego 1, 30-705 Krakow, Poland. E-mail: gdebska@afm.edu.pl

https://doi.org/10.21101/cejph.a4305

\section{INTRODUCTION}

Nurses working at chemotherapy wards take care of patients with severe illness, for whom anticancer treatment, which causes a number of side effects, is a traumatic experience. Moreover, the job is often accompanied by emotional reactions associated with depressive states, fear of death and suffering. Without a doubt, such working conditions carry the risk of psychological strain, both mental and emotional (1). One of the instruments measuring mental load is a standardized Meister questionnaire. It is used for subjective assessment of the effect occupational activity has on the employee's psyche in three dimensions: Overload, Monotony and Unspecific Load (non-specific reaction to stress) (2).

Early diagnosis and counter-measures aimed at reducing mental load rely heavily on the individual's ability to cope with stress. The efficiency of this strategy depends on the individual potential abilities, i.e. the sense of coherence. According to Antonovsky, coherence is "the global orientation of a human being, in which a person has the dominant, permanent, albeit dynamic, feeling of certainty that the stimuli provided in the course of life by the internal and external environment are structured, predictable and explicable; there are available resources, which help face the challenges arising from these stimuli, thus these challenges are a worthwhile effort...” (3). In this context, a high level of coherence seems to directly affect one's mental load.

Therefore, the aim of this study was to analyze the relationship between the levels of Coherence and Mental Load among nurses working at a chemotherapy ward. Based on this aim, the following research questions were formulated: "Is there an association between the levels of Coherence and Mental Load among nurses working at a chemotherapy ward?”; "Is there a relationship between the levels of Coherence and Mental Load and the educational level, age and work experience of nurses?”; and "Which factors affect the level of dissatisfaction among the studied population?”

\section{MATERIALS AND METHODS}

The protocol of the study, conducted in 2013, was approved by the Local Bioethics Committee at Andrzej Frycz Modrzewski Krakow University (Decision No. 2/2013).

The study included 164 nurses working at inpatient chemotherapy wards in Krakow, Poznan, Kielce, and Gliwice (Poland). The mean age of the study participants was $43.07 \pm 7.99$ years (range 23-60 years), and their mean work experience at a chemotherapy ward amounted to $11.77 \pm 7.65$ years. A total of 58 (35.4\%) participants came from rural backgrounds, 51 (31\%) from towns up to 35,000 inhabitants, 55 (33.6\%) from cities over 35,000 inhabitants.

The study was based on a diagnostic survey, using two questionnaires: Antonovsky's Sense of Coherence Scale (SOC-29), and Meister questionnaire. SOC-29 was used to determine the level of Coherence and its three dimensions, i.e. Comprehensibility, 
Manageability and Meaningfulness (3, 4). The questionnaire was adapted for Polish conditions in 1993 (5). Meister questionnaire, adapted for Polish conditions by Dębska, Wilczek-Rużyczka et al. was used to assess the level of Mental Load (6). Polish version of the instrument satisfies the criteria of an accurate and reliable tool (Cronbach's alpha 0.83). We used Meister questionnaire to determine three dimensions of Mental Load: Overload, Monotony and Non-specific Load, based on Hladký and Židková interpretative key (2). The results were presented as mean values, standard deviations, ranges, and minimum and maximum values. Furthermore, the median values for all the Mental Load dimensions were compared with respective critical normalized values proposed by Hladký and Židková $(2,7,8)$. The answers to the first and second research questions were based on the analysis of Pearson's correlation coefficients; the values 0.1 to 0.3 were considered as weak correlations, 0.3 to 0.6 as moderate correlations, and 0.6 to 1.0 as very strong correlations. The results of all tests were considered significant at $\mathrm{p}<0.05$.

\section{RESULTS}

\section{Descriptive Statistics}

Descriptive statistics for the studied parameters are presented in Tables 1 and 2. The mean level of Coherence was $125.05 \pm 18.30$ (range 70-185). The highest scores were documented for the Manageability subscale (45.15), followed by the Comprehensibility and Meaningfulness subscales (41.18 and 38.73, respectively) (Table 1).

Although the mean level of Mental Load was 26.18, the median value for this parameter (26) did not exceed the respective critical limit. The median value for Overload, one of the Mental Load dimensions, amounted to 10 and exceeded the respective critical limit. The median values of another two dimensions of Mental Load, i.e. Monotony and Unspecific Load (reaction to stress) equaled 5 and 11 , respectively (Table 2).

The median values for all three items included in the Overload subscale, i.e. Time Pressure, Great Responsibility and Problems and Conflicts, exceeded the respective critical limits. The median values for the Monotony subscale items, i.e. Low Satisfaction,
Dull Work and Monotony, remained within the respective critical limits. The median values for three Unspecific Load subscale items, i.e. Nervousness, Oversaturation and Fatigue, equaled their critical limits. One of the items included in this subscale, namely Long-lasting Load, scored 4, thus exceeding the respective critical limit (Table 3).

\section{Relationships Between Coherence and Mental Load Dimensions}

To verify relationships between the measures of Coherence and Mental Load, we have determined Pearson's correlation coefficients between various dimensions of the two parameters.

We showed that the level of Overload did not correlate significantly with any of the Coherence dimensions. An increase in the level of Monotony turned out to be associated with a moderate degree decrease in the Coherence, Manageability and Meaningfulness levels, as well as with a slight decrease in the Comprehensibility level. Also, an increase in the level of Unspecific Load was associated with a slight decrease of the Manageability and Comprehensibility levels, as well as with a moderate degree decrease in the levels of Meaningfulness and Coherence. Finally, an increase of the overall Mental Load turned out to be reflected by a moderate degree decrease in the Coherence, Manageability and Meaningfulness levels, and by a slight decrease in the level of Comprehensibility (Table 4).

\section{Relationships Between Coherence and Mental Load Dimensions, Educational Level, Work Experience and Age}

To examine relationships between the Coherence and Mental Load dimensions, educational level, work experience and age, we have determined Pearson's correlation coefficients between these variables.

We showed that work experience correlated positively with the levels of Overload, Monotony and overall Mental Load; however, all these correlations were weak. Moreover, an increase in the work experience was associated with a decrease in the levels of Manageability $(\mathrm{r}=-0.18, \mathrm{p}=0.024)$, Comprehensibility $(\mathrm{r}=-0.17$,

Table 1. Descriptive statistics for the sense of coherence measures (Antonovsky's Sense of Coherence Scale, SOC-29)

\begin{tabular}{|l|c|c|c|c|c|c|c|}
\hline Parameter & Mean & Standard error & Median & $\begin{array}{c}\text { Standard } \\
\text { deviation }\end{array}$ & Range & Minimum & Maximum \\
\hline Manageability & 45.15 & 0.58 & 44 & 7.41 & 46 & 20 & 66 \\
\hline Comprehensibility & 41.18 & 0.59 & 41 & 7.58 & 48 & 18 & 66 \\
\hline Meaningfulness & 38.73 & 0.56 & 38 & 7.14 & 34 & 22 & 56 \\
\hline Coherence & 125.05 & 1.43 & 124 & 18.30 & 115 & 70 & 185 \\
\hline
\end{tabular}

Table 2. Descriptive statistics for the mental load measures (Meister questionnaire)

\begin{tabular}{|l|c|c|c|c|c|c|}
\hline Parameter & Mean & Median & Standard deviation & Minimum & Maximum & Critical limit $^{1}$ \\
\hline Overload & 9.96 & $10^{\#}$ & 2.27 & 4 & 15 & 8 \\
\hline Monotony & 5.30 & 5 & 2.21 & 2 & 15 & 9 \\
\hline Unspecific Load & 10.92 & 11 & 3.70 & 4 & 20 & 14 \\
\hline Mental load & 26.18 & 26 & 6.65 & 12 & 50 & 29 \\
\hline
\end{tabular}

${ }^{1}$ According to Židková et al. (7); "denotes exceeded critical limit 
Table 3. Descriptive statistics for the individual items of Meister questionnaire

\begin{tabular}{|l|c|c|c|c|}
\hline Item & Mean & Standard deviation & Median & Critical limit $^{1}$ \\
\hline Time pressure & 4.07 & 0.99 & $4^{\#}$ & 3 \\
\hline Low satisfaction & 1.96 & 0.99 & 2 & 2 \\
\hline Great responsibility & 3.73 & 1.17 & $4^{\#}$ & 2 \\
\hline Dull work & 1.67 & 0.84 & 1 & 2 \\
\hline Problems and conflicts & 2.18 & 1.11 & $2^{\#}$ & 1 \\
\hline Monotony & 1.71 & 0.91 & 1 & 2 \\
\hline Nervousness & 2.56 & 1.12 & 2 & 2 \\
\hline Oversaturation & 2.02 & 1.06 & 2 & 3 \\
\hline Fatigue & 3.00 & 1.26 & 3 & 3 \\
\hline Long-lasting load & 3.27 & 1.21 & $4^{\#}$ & \\
\hline
\end{tabular}

${ }^{1}$ According to Židková (8); "denotes exceeded critical limit

Table 4. Pearson's coefficients of correlation ( $r$ ) between the dimensions of coherence and mental load

\begin{tabular}{|l|l|c|c|c|c|}
\hline \multicolumn{2}{|l}{ Parameter } & Manageability & Comprehensibility & Meaningfulness & Coherence \\
\hline \multirow{2}{*}{ Overload } & $\mathrm{r}$ & -0.148 & -0.061 & -0.056 & -0.107 \\
\cline { 2 - 6 } & $\mathrm{p}$ & 0.058 & 0.438 & 0.474 & 0.172 \\
\hline \multirow{3}{*}{ Monotony } & $\mathrm{r}$ & $-0.300^{* *}$ & $-0.259^{* *}$ & $-0.436^{* *}$ & $-0.398^{* *}$ \\
\cline { 2 - 6 } & $\mathrm{p}$ & $<0.001$ & 0.001 & $<0.001$ & $<0.001$ \\
\hline \multirow{2}{*}{ Unspecific load } & $\mathrm{r}$ & $-0.287^{* *}$ & $-0.251^{* *}$ & $-0.383^{* *}$ & $-0.370^{* *}$ \\
\cline { 2 - 6 } & $\mathrm{p}$ & $<0.001$ & 0.001 & $<0.001$ & $<0.001$ \\
\hline \multirow{2}{*}{ Mental load } & $\mathrm{r}$ & $-0.313^{* *}$ & $-0.249^{* *}$ & $-0.380^{* *}$ & $-0.378^{* *}$ \\
\cline { 2 - 6 } & $\mathrm{p}$ & $<0.001$ & 0.001 & $<0.001$ & $<0.001$ \\
\hline
\end{tabular}

${ }^{* *}$ Correlation significant at $p<0.01$

$\mathrm{p}=0.034)$ and overall Coherence $(\mathrm{r}=-0.19, \mathrm{p}=0.016)$; however, $\quad$ associated with a decrease in the level of Manageability; also this also these correlations turned out to be weak. We also found a correlation was weak. The remaining dimensions of Coherence weak inverse correlation between age and Comprehensibility and Mental Load did not correlate significantly with educational level $(\mathrm{r}=-0.19, \mathrm{p}=0.014)$. Moreover, older age turned out to be level, work experience and age of the study participants (Table 5).

Table 5. Pearson's coefficients of correlation (r) between the dimensions of coherence and mental load, educational level, work experience and age

\begin{tabular}{|l|l|c|c|c|}
\hline Parameter & & Education & Experience & Age \\
\hline \multirow{3}{*}{ Overload } & $\mathrm{r}$ & 0.043 & $0.175^{*}$ & 0.078 \\
\cline { 2 - 5 } & $\mathrm{p}$ & 0.581 & 0.026 & 0.322 \\
\hline \multirow{3}{*}{ Unspecific Load } & $\mathrm{r}$ & -0.062 & $0.175^{*}$ & -0.053 \\
\cline { 2 - 5 } & $\mathrm{p}$ & 0.432 & 0.026 & 0.497 \\
\hline \multirow{3}{*}{ Mental Load } & $\mathrm{r}$ & 0.084 & 0.089 & 0.043 \\
\hline \multirow{2}{*}{ Manageability } & $\mathrm{p}$ & 0.286 & 0.261 & 0.585 \\
\hline \multirow{2}{*}{ Comprehensibility } & $\mathrm{r}$ & 0.041 & $0.168^{*}$ & 0.033 \\
\cline { 2 - 5 } & $\mathrm{p}$ & 0.602 & 0.034 & 0.675 \\
\cline { 2 - 5 } & $\mathrm{r}$ & 0.047 & $-0.178^{*}$ & $-0.193^{*}$ \\
\hline \multirow{2}{*}{ Meaningfulness } & $\mathrm{p}$ & 0.551 & 0.024 & 0.014 \\
\hline \multirow{2}{*}{ Coherence } & $\mathrm{r}$ & 0.051 & $-0.168^{*}$ & -0.019 \\
\cline { 2 - 5 } & $\mathrm{p}$ & 0.520 & 0.034 & 0.812 \\
\cline { 2 - 5 } & $\mathrm{r}$ & 0.000 & -0.123 & -0.137 \\
\hline
\end{tabular}


Table 6. Factors causing dissatisfaction of the study participants $(N=164)$

\begin{tabular}{|l|c|c|}
\hline Factors causing dissatisfaction & $\mathbf{n}$ & $\%$ \\
\hline Bad atmosphere at the workplace & 40 & 24.5 \\
\hline Low pay & 101 & 62.0 \\
\hline Low professional status & 75 & 46.0 \\
\hline Great responsibility & 57 & 35.0 \\
\hline Limited access to decision-making & 27 & 16.6 \\
\hline Bad treatment from the superiors & 22 & 13.5 \\
\hline Disproportion between the number of nurses and patients in need & 69 & 42.3 \\
\hline Shift work & 20 & 12.3 \\
\hline Heavy mental and physical workload & 104 & 63.8 \\
\hline Contact with death and suffering & 46 & 28.2 \\
\hline Inability to reconcile work and private life & 8 & 4.9 \\
\hline Other factors & 7 & 4.3 \\
\hline
\end{tabular}

\section{Factors Causing Dissatisfaction}

To answer to the research question "Which factors affect the level of dissatisfaction among the studied population?" we have conducted a frequency analysis.

Heavy mental and physical workload (63.8\%) turned out to be the main factor causing dissatisfaction of the study participants, followed by low pay (62\%), low professional status (46\%), disproportion between the number of nurses and patients (42.3\%), great responsibility (35\%), contact with death and suffering (28.2\%), bad atmosphere at the workplace (24.5\%), limited access to decision-making (16.6\%), bad treatment from the superiors (13.5\%), shift work (12.3\%), inability to reconcile work and private life (4.9\%), and other factors (4.3\%) (Table 6).

\section{DISCUSSION}

The job of a nurse working at a chemotherapy ward is affected by a number of factors. The most significant ones are associated with being in contact with patients diagnosed with cancer and with being in charge of a straining, long-term treatment. The second specific factor is becoming mentally involved, by developing attachment to the patients and their families as a result of repetitive treatment (a number of chemotherapy cycles, usually every three weeks). Apart from interdisciplinary knowledge, providing nursing care to a patient primed for treatment requires the ability and skills of diagnosing and undertaking appropriate interventions. Also, the everyday work-organization of the ward associated with heavy rotation of the patients and the need to follow the requirements for preparing and administering medications to the patients become the source of mental load. There is no doubt that for a nurse working in such work-environment, the sense of coherence, which strengthens the resources related to broadly defined "mental health," is significant. Thus, a vital research question for this study was ascertaining whether the level of Coherence is associated with Mental Load, age and work experience, and what types of burden are the most frequent. We have used reliable tools with verified psychometric characteristics to assess the levels of Mental Load and Coherence and associations thereof with the job performed on a given position.
We showed that the median level of one of the Mental Load dimensions, namely Overload, exceeded its critical limit proposed by Židková (10 vs. 8) (8). The median values of another two Mental Load dimensions, i.e. Monotony and Unspecific Load, did not exceed the respective critical limits. The analysis of the ranks assigned to the particular items from the Meister questionnaire showed that the greatest strain experiences by our participants resulted from Time Pressure, Great Responsibility, Fatigue, and Long-lasting Load. This is consistent with the results of the Slovak (9) and Czech studies $(10,11)$. The Slovak study documented a relationship between mental load, depression and mood in the group of 78 nurses (9), and the Czech studies showed the differences in the perception of mental load in the context of certain professions, inter alia medical professions (10, 11). Similar to the hereby reported results, the median levels of Time Pressure, Great Responsibility, Fatigue and Long-lasting Load documented in the two above-mentioned studies exceeded the respective critical limits (9-11). Previous study conducted by Dębska et al. (12) showed that the level of Mental Load in oncology nurses is significantly higher than in nurses working at other wards. Furthermore, the levels of Mental Load for oncology nurses exceeded respective critical limits for similar dimensions as in the present study (12). Other studies conducted by Dębska et al. (13-15) showed that Overload and Monotony are specialization-inherent factors that differentiate the workplace. Nurses working with Alzheimer's disease patients experienced mental overload and fatigue, but still managed to draw satisfaction from their work (15). Also Židková (8) assessed the level of Mental Load associated with work at different positions. She used Meister questionnaire to examine a group of 1,832 subjects, among them 1,300 females with the results that did not reach critical values. The levels of Mental Load for the whole study group did not exceed the respective critical limits. However, the subgroup analysis of employees performing the same job showed that the critical limits were exceeded in case of Overload for doctors and Unspecific Load for scrub nurses (8).

Although our nurses presented with moderate levels of Coherence and its dimensions, the individual results varied considerably. Nevertheless, the levels of Coherence documented in our study group are similar to those reported previously by Kocięcka et 
al. (16) and Urbańska and Kurowska (17). The studies showed association between the levels of Coherence, health status and health behaviours of nurses $(16,17)$. This relationship was also confirmed in another study in which nurses showing higher motivation to quit smoking were characterized by a stronger sense of Coherence (18).

We showed that Overload did not correlate significantly with any of the Coherence dimensions. In turn, an increase of the level of Monotony turned out to be reflected by a decrease in the global Coherence, Manageability and Meaningfulness levels. Furthermore, an increase in the level of Unspecific Load, a measure of stress reaction, was associated with a decrease in the global Coherence, Manageability, Meaningfulness and Comprehensibility levels. Consequently, the low level of global Coherence and its dimensions promoted an increase in the levels of Mental Load.

Heavy mental and physical workload, low pay, low professional status, disproportion between the number of nurses and patients, and terminal status of the latter turned out to be the most frequently listed occupational stressors in our group. Similar results were previously reported by Sęk et al. (19), who identified the following stressors inherent to nursing profession: expectations arising from the specifics of the profession, overload caused by the feelings of responsibility, lack of appropriate treatment conditions, low pay, low social status, bad cooperation within the therapeutic team and with the patient and his or her family. Other studies have shown that the greatest risks and burdens experienced by community nurses include physical strain, forced body position, aggression from the patients and their families, dangerous pets, and bad technical condition of the appliances at the patient's home (19). According to Tartas et al. (20), hospice nurses differ from general surgery nurses in terms of some of the specific work-related stressors. Hospice nurses more frequently experience discomfort associated with limited opportunities for professional development, conflicts with superiors and contacts with the patient's family. In contrast, they do not differ from surgical nurses in terms of the discomfort experienced due to workload, organizational and technical conditions, cooperation within the therapeutic team, and contact with the patients (20). Nurses working in emergency wards experience higher levels of Occupational Burnout with regards to Emotional Exhaustion and Depersonalization, which is associated with more frequent thoughts about dying (21).

There is no doubt that for nurses working at chemotherapy wards dealing with disease, suffering and death becomes everyday routine. According to Kurowska et al. $(22,23)$, the differences in the level of Occupational Burnout presented by oncology nurses arise from the specifics of the position, age and work experience. The same authors pointed to the associations between the levels of Coherence, Personal Accomplishments and Emotional Exhaustion (22, 23). Also Ježorská et al. (24) documented a relationship between the amount of work of oncology nurses and the level of their Occupational Burnout.

Kadučáková and Lehotská (25) showed that the main factor exerting negative influence on the work of nurses employed at social care homes are too many duties, and resultant time pressure and fatigue. However, it was aggression from patients and their families which turned out to have the greatest influence on the nurses' burden (25).
Our hereby presented findings are consistent with the results of a study involving a group of psychiatric nurses conducted by Płotka et al. (26). Also the participants of this study identified pay system (74.5\%), threats to personal security (63.6\%) and working overtime (31.8\%) as the most straining factors inherent to a nurse's job (26). These data confirm the hypothesis that a strong sense of coherence is an individual resource necessary for dealing with stress factors. High level of coherence lowers the level of stress and attenuates its negative consequences. Midwives and midwifery students were shown to differ in terms of their sense of coherence and stress-resistance, with the midwives scoring markedly higher than participants of any previous study. The levels of Manageability and Comprehensibility were shown to correlate with resistance to stress in some groups of midwives, midwifery and nursing students $(27,28)$.

Nurses working at chemotherapy wards are constantly exposed to many stressors, which can be the reason for their mental load. High levels of Mental Load are predominantly the result of personal involvement in the life of sick, suffering people, which is associated with the specifics of the performed job. Even though the employer is responsible for minimizing mental load, the nurses themselves should also take care of their psychological wellbeing by strengthening their sense of coherence; as a result, their work environment will become clear, explicable and comprehensive, and they will perceive themselves as resourceful.

The survey results cannot be generalized to the entire population of nurses working with oncological patients because the variable, which is psychological stress, is conditioned by many factors such as personality and environment, which were not analyzed.

The survey results just show a certain tendency as factors influencing psychological burden are difficult to measure objectively. The obtained results can be used for the organization of nursing care, occupational medicine and nursing managerial staff.

\section{CONCLUSIONS}

Work experience is associated with the levels of some of the Coherence and Mental Load dimensions: the longer the work experience the lower the level of Manageability and Comprehensibility and the higher the level of Mental Load in terms of Overload and Monotony. There is an association between age and the Manageability level: the older the nurse the lower her level of Manageability. The levels of Coherence and Mental Load (apart from Overload) correlate with each other in chemotherapy nurses. The lower the level of Coherence the higher the risk of mental overload. The most frequently listed work-related burdens of nurses include heavy mental and physical workload, low pay, low professional status, disproportion between the number of nurses and patients, and terminal status of the latter.

\section{Conflict of Interests}

None declared

\section{Funding}

The study was financed with the use of funds from the Ministry of Science and Higher Education for scientific and development research within its status activity (numer of research task: WZiNM/DS/7/2015-KON 


\section{REFERENCES}

1. Szczurak T, Kamińska B, Szpak A. Subjective symptoms of burnout at a nurse's workplace in determination of mental load. In: Krajewska-Kułak E, Szczepański M, Łukaszuk C, Lewko J, editors. Therapeutic and nursing problems: from conception to senility. Vol. 2. Bialystok: Medical University of Bialystok; 2007. p. 310-5. (In Polish.)

2. Hladký A, Židková Z. Methods for assessing occupational psychosocial load. Prague: Karolinum; 1999. (In Czech.)

3. Antonovsky A. Unraveling the mystery of health: how people manage stress and stay well. Warsaw: Institute of Psychiatry and Neurology; 2005. (In Polish.)

4. Antonovsky A. The structure and properties of the sense of coherence scale. Soc Sci Med. 1993 Mar;36(6):725-33.

5. Koniarek J, Dudek B, Makowska Z. Orientation to Life Questionnaire. Adaptation of the Sense of Coherence Questionnaire (SOC) by A. Antonovsky. Przegl Psychol. 1993;36(4):491-502. (In Polish.)

6. Dębska G, Wilczek-Rużyczka E, Foryś Z, Pasek M. Psychometric properties assessment of the Meister questionnaire (Polish version) used in evaluating mental load among nurses. Med Pracy. 2013;64(3):349-58. (In Polish.)

7. Židková Z, Martinková J, Paulová M, Svačinková M. The psychological burden of ancillary health-care personnel. Cesk Prac Lek. 2001;2(1):1620. (In Czech.)

8. Židková $Z$. The application of questionnaire in the evaluation of psychic load at work. Cesk Prac Lek. 2002;3(2):128-32. (In Czech.)

9. Gurková E, Macejková S. Psychological strain and depressive symptomatology between nurses. Osetr Porod Asist. 2012;3(1):326-34. (In Slovak.)

10. Hodačová L, Šmejkalová J, Skalská H, Bendová M. Differences in occupational psychic load perception among workers of chosen professional groups. Lék Zpr Lek Fak Univ Karlovy Hr Králové. 2007;52(2):93-103. (In Czech.)

11. Zálešáková J, Bužgová R. Psychological stress of nurses taking care of cancer patients. Prac Lek. 2011;63(3-4):113-8. (In Czech.)

12. Dębska G, Pasek M, Wilczek-Rużyczka E, Foryś Z. Psychological burden experienced by nurses in oncology units vs. nurses employed in other medical units. In: Moravčíková D, Vaško M, editors. Family - Health Disease 2013: Proceedings of the International Conference on Health Care Studies; 2013 Oct 10; Zlín, Czech Republic. Zlín: Tomas Bata University in Zlín; 2014. p. 109-18.

13. Dębska G, Pasek M, Wilczek-Rużyczka E. Psychological strain and occupational burnout among nurses of various specialties. Hygeia Publ Health. 2014;49(1):113-9. (In Polish.)

14. Dębska G, Cepuch G, Pasek M, Filiciak B. Psychosocial load of community nurses involved in long-term care. In: Lacko A, Lesňáková A, Minarik M, Zrubáková K, editors. Seventh Ružomberok Days for Health 2012: International Conference Proceedings. Ružomberok: Verbum; 2012. p. 333-45. (In Polish.)
15. Dębska G, Pasek M, Zięba M. Analysis of strain placed on nurses working with patients with Alzheimer's disease. Stud Sci Fac Pedagog. 2013;12(5):23-30

16. Kocięcka A, Andruszkiewicz A, Wrońska I. A sense of coherence and the health of professionally active nurses. Probl Pielęgniarstwa. 2010;18(2):139-44. (In Polish.)

17. Urbańska B, Kurowska K. Sense of coherence (SOC) versus health behaviour in nurses. Pielęgni Chir Angiol. 2010;(3):90-5. (In Polish.)

18. Andruszkiewicz A, Basińska MA. Sense of coherence and dependence on nicotine. Probl Pielęgniarstwa. 2008;16(1-2):123-7. (In Polish.)

19. Sęk H, Beisert M, Pasikowski T, Ścigała J. Mechanisms of occupational stress and burnout in a cognitive-competence model. In: Tokarz, A, Nęcki Z, Kawalec M, editors. Cognitive psychology in Poland: concepts, analyses and research. Warsaw: Institute of Psychology, Polish Academy of Sciences; 1997. (In Polish.)

20. Tartas M, Derewicz G, Walkiewicz M, Budziński W. Sources of job stress among nurses in hospice and surgical ward. Ann Acad Med Gedan. 2009;39:145-53. (In Polish.)

21. Lewko J, Mielech D, Nyklewicz W, Lukaszuk C, Sierakowska M, Kowalczuk K, et al. Beliefs about death and dying among ambulance nurses and the burnout syndrome. Probl. Pielęgniarstwa. 2009;17(2):92-7. (In Polish.)

22. Kurowska K, Zuza-Witkowska A. Empathy and occupational burnout of oncological nurses. Nowiny Lek. 2011;80(4):277-82. (In Polish.)

23. Kurowska K, Maciaszek A, Haor B, Rezmerska L. Sense of coherence and occupational burnout in profesionally active nurses. Pielęgn Chir Angiol. 2011;(1):23-30. (In Polish.)

24. Ježorská Š, Kozyková J, Chrastina J. Burnout syndrome among oncology nurses. Ošetrovatelstvo. 2012;2(2):56-62. (In Czech.)

25. Kadučáková $H$, Lehotská $M$. Determinants of a nurse's job at social care centers. In: Dębska G, Jaśkiewicz J, editors. Interdisciplinary aspects of health sciences. Krakow; AFM: 2010. p. 177-83. (In Polish.)

26. Płotka A, Golec D, Czernikiewicz A. Burnout syndrome in psychiatric nurses. Ann Univ Mariae Curie Sklodowska Med. 2000;55 Suppl 7:22937. (In Polish.)

27. Łapińska M, Gaworska-Krzemińska A, Dominiak K, Milewski M, Zawadzka J, Kretowicz K, et al. Sense of coherence and stress resistance among midwives as predictors of professional autonomy. Probl Pielęgniarstwa. 2013;21(3):306-17. (In Polish.)

28. Kretowicz K, Grzegorczyk M, Gaworska-Krzemińska A, Świetlik D. The sense of coherence and resistance to stress among part-time nursing students doing a bachelor degree. In: Czajkowska-Ziobrowska D, editor. Academic areas of scientific knowledge. Poznań: Altus; 2011. p. 125-40.

Received February 12, 2015 Accepted in revised form November 19, 2016 